
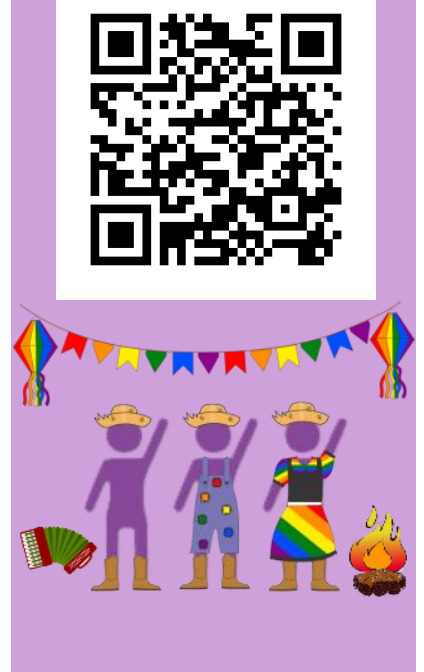

\title{
Campanhas antigênero, populismo e neoliberalismo na Europa e na América Latina
}

Éric Fassin, Universidade Paris 8

Tradução: Mariana Duarte e Diego Paz

Resumo: Este artigo foi publicado inicialmente sob o título Anti-gender Campaigns, Populism, and Neoliberalism in Europe and Latin America na revista do Forum da LASA (Latin American Studies Association) no dossiê Las ofensivas antigénero em América Latina (51, 2, 67-71). Em seguida, foi publicado e em francês sob o título Campagnes anti-genre, populisme et néolibéralisme en Europe et en Amérique latine, ne Revue Internationale et Stratégique (RIS), dentro do dossiê temático La géopolitique par le genre: des réflexions aux nouveaux répertoires d'action (119, 3, 79-87).

Palavras-Chave: Antigênero. Populismo. Neoliberalismo. França. Brasil. 

Em 2012, a França foi o teatro de massivos protestos contra a lei que abria a possibilidade do casamento civil - e, assim, da adoção - aos casais de pessoas do mesmo sexo. Eles retomaram e ampliaram as mobilizações do fim dos anos 1990 contra o Pacto civil de solidariedade $(\mathrm{PaCS})^{1}$, a primeira versão de união civil permitida a todos os casais. Contudo, o contexto havia mudado consideravelmente: de fato, em vinte anos, a igualdade de direitos havia conquistado a opinião pública. Consequentemente, personalidades políticas e intelectuais que reivindicavam de uma posição socialdemocrata, antes contrárias ao PaCS, agora apoiavam o "casamento igualitário" ("Mariage pour tous")². Apenas conservadoras e conservadores insistiam em sua posição contrária - com uma determinação ainda mais forte. Havia outras diferenças significativas entre as duas mobilizações. Particularmente, nos anos 2010, a Igreja católica francesa "saiu de seu armário laico". Até então, ao contrário dos Estados Unidos, as referências religiosas se encontravam ausentes do debate público francês - mesmo no que concerne a homossexualidade. Com a "Manif pour tous"3, líderes religiosos e seus fiéis se sentiram autorizados a desfilar pelas ruas de Paris: nessa nova era da celebração da identidade nacional, a invocação da "laicidade" como princípio fundador da República francesa se aplicava, nesse momento, apenas à religião islâmica.

\footnotetext{
${ }^{1}$ Nota da tradutora e do tradutor (Ntd.): Salvas as devidas proporções, o Pacto civil de solidariedade (em francês, Pacte civil de solidarité), ou simplesmente PaCS, pode ser equiparado, do ponto de vista da legislação brasileira, ao contrato de União estável.

2 Ntd.: Optamos pelo termo "casamento igualitário", pois foi como ficou conhecido o movimento pela legalização do casamento entre pessoas do mesmo sexo no Brasil. Esse termo melhor representa o movimento análogo francês, conhecido por Mariage pour tous, cuja tradução direta seria Casamento para todos. No intuito de situar o debate brasileiro, podemos destacar que, em síntese: em 1995, a deputada Marta Suplicy (Partido dos Trabalhadores, PT) apresenta o Projeto-Lei 1.151-A que propõe a união civil entre pessoas do mesmo sexo, que não logrou aprovação, mas contribuiu para que o tema alcançasse o debate público. Em 5 de maio de 2011, o Supremo Tribunal Federal (STF) decidiu unanimemente que a união estável entre pessoas do mesmo sexo é uma entidade familiar, atribuindolhes os mesmos direitos que casais heterossexuais também teriam se sujeitos ao mesmo regime. Em 14 de maio de 2013, o Conselho Nacional de Justiça (CNJ), através da resolução n. 175, determina aos cartórios a obrigatoriedade de celebração de casamento civil ou de conversão de união estável em casamento, sem a necessidade de um processo em justiça. Finalmente, no mesmo ano, o então deputado federal Jean Wyllys (PSOL-RJ) e a deputada federal Érika Kokay (PT-DF) protocolaram na Câmara dos Deputados um projeto de lei(PL) que pretende garantir o direito ao "casamento civil igualitário" a partir da revisão dos termos "entre homem e mulher" presente no artigo 226 da Constituição Federal. O PL segue em tramitação e sem previsão de ser votado em plenária.

3 Ntd.: Podendo ser traduzido literalmente por "Protesto para todos" ou "Manifestação para todos", o movimento reacionário conhecido como Manif pour tous se organizou em torno da oposição ao casamento entre pessoas do mesmo sexo na França. O próprio termo Manif pour tous é um trocadilho com o termo Mariage pour tous, que lutava pelo casamento igualitário nesse país, o que mostra uma oposição explícita.
} 
Essa mudança abriu caminho para uma retórica contra a dita "ideologia de gênero". A formulação análoga francesa, "teoria do gênero", ressalta outra diferença que aparece após os anos 2010: se conservadores e reacionários há muito tempo tem lutado contra os direitos das mulheres e das minorias sexuais, a novidade da última década foi a atenção dada especificamente ao conceito de gênero. Isso significa que a defesa da ordem sexual vai agora ombro a ombro com o ataque ao campo dos estudos de gênero. Não se trata de mirar unicamente nos direitos reprodutivos ou no reconhecimento legal dos casais do mesmo sexo, mas também de lançar uma ofensiva contra os fundamentos teóricos e, consequentemente, contra os estudos feministas e queer. Por isso, foi dada uma atenção excepcional dirigida ao que, até então, não parecia nada senão um conceito técnico, restrito inicialmente aos círculos médicos, aos estudos feministas e, enfim, às instituições internacionais.

Na França, um slogan resumia essa equação: "casamento igualitário = teoria do gênero para todos" ("mariage pour tous = théorie du genre pour tous"). O que estava em jogo, por um lado, era a ideia de que o sexo é definido de uma vez por todas em termos biológicos. Por exemplo, em um outro cartaz nas manifestações lia-se: "Não há óvulos nos testículos!" (“Pas d'ovules dans les testicules !"). Por outro lado, contudo, essa ordem sexual deveria ser absolutamente preservada pelo casamento heterossexual, definido pelo oximoro: "uma instituição natural". De onde vem a reabilitação dos códigos de cor segundo o gênero - rosa para meninas, azul para meninos - combinado às palavras de ordem: "Não toquem nos nossos estereótipos de gênero!". Em 2011, os ataques vindos de católicos e católicas e da extrema direita contra os livros de biologia, acusados de ensinar um "feminismo ideológico" aos estudantes do ensino médio, serviram de ensaio geral para a poderosa campanha religiosa e política contra a "teoria do gênero", que começou em 2012 contra o "casamento homossexual" e se estendeu para além da lei Taubira de $2013^{4}$.

Os ataques teóricos visando o conceito de gênero lançados pelo Vaticano (GARBAGNOLI; PREARO, 2017) - que começaram na Conferência mundial sobre a mulher, organizado pelas Nações unidas em Pequim, em 1995; a partir do polêmico ensaio da militante católica Dale O’Leary, The Gender Agenda, publicado em 1997, sucedido da "Carta aos

\footnotetext{
4 Ntd.: Em referência à lei francesa 404, de 17 de maio de 2013, defendida por Christiane Taubira, do Partido Radical de Esquerda (Parti radical de gauche, PRG) e então ministra da justiça (2012-2016), permitindo que pessoas do mesmo sexo tivessem acesso ao casamento civil na França.
} 
bispos da igreja católica sobre a colaboração do homem e da mulher na igreja e no mundo" de 2004 e a publicação, em 2005, em francês, do Léxico de termos ambíguos e controversos sobre a família, a vida e as questões éticas (Lexique des termes ambigus et controversés sur la famille, la vie et les questions éthiques) - desceram às ruas da França laica. Elas encontraram um eco, tanto na Câmara dos deputados (Assemblée Nationale) como no Senado (Sénat). Nessa combinação paradoxal de catolicismo secular (ou secularismo católico), resumida pelo termo "catolaicidade" ("catholaïcité"), a França era uma exceção: o casamento de pessoas do mesmo sexo não tinha sido legalizado antes de 2013 em países católicos, como a Espanha em 2005 ou a Argentina em 2010, sem provocar tais manifestação ou sem a retórica antigênero?

Na realidade, as mobilizações francesas contra os estudos de gênero não são em nada excepcionais (exceto o termo "teoria", no sintagma "teoria do gênero"). Ao contrário: vários países europeus davam sinais de alerta de uma ofensiva antigênero, começando com a Espanha em meados de 2000, e então na Croácia, Itália e Eslovênia. Essas campanhas estavam em pleno desenvolvimento e tiveram seu auge por volta de 2013, com a criação nas redes sociais da plataforma CitizenGO, também na Espanha, e com a rejeição do Relatório Estrela sobre "Saúde e Direitos Sexuais e Reprodutivos" no Parlamento Europeu.

Na América Latina, para dar um exemplo, Rafael Correa, então presidente do Equador, proferiu severas críticas à "ideologia de gênero", na televisão em 2014, acusando-a de representar uma ameaça para as famílias. Em inúmeros países, em ambos os continentes, o combate visando restaurar uma ordem sexual tradicional agora coincide com as campanhas contra a supostamente nefasta "ideologia do gênero".

Embora o surto alcança também os Estados Unidos e muitos países africanos, a Europa e a América Latina se mostram os mais atingidos. Os ataques contra o gênero reforçaram as campanhas tradicionais contra os direitos reprodutivos que, literalmente, atravessaram o continente - de ônibus, do México ao Chile - elas até mesmo enfraqueceram as negociações pela paz na Colômbia. Essa virada, que podemos qualificar de "fobia do gênero" ("genderophobic turn"), foi particularmente percebida no Brasil: desde o ataque a uma efígie de Judith Butler, queimada em São Paulo em 2017, até a disseminação de fake news sobre um suposto "kit gay" nas escolas que foram usadas na campanha contra o candidato do Partido dos Trabalhadores, Fernando Haddad, em 2018. A política antigênero pôde então encontrar seu lugar na política oficial: em janeiro 
2019, durante a seu juramento, a ministra da Mulher, da Família e dos direitos humanos, Damares Alves, pastora evangélica, ilustrou seu apelo à uma "nova era" para o Brasil, escolhendo os mesmos estereótipos anteriormente utilizados na campanha antigênero francesa: "menino veste azul e menina veste rosa”.

Ficou claro, então, que as mobilizações antigênero não são uma exclusividade francesa, e que não se trata apenas de "francesismo". Essas campanhas se propagaram desde as culturas católicas (como a Polônia e a Hungria, a Colômbia e a Argentina) até as evangélicas (como o Brasil e os Estados unidos) e as ortodoxas (como a Rússia). Sem esquecer as culturas laicas (não somente a França, mas também o Uruguai). A religião talvez não seja, de fato, a causa última das políticas antigênero, mas um dos seus vetores favoritos: em cada país, o elemento crucial é a convergência de diversas lógicas conservadoras e reacionárias, religiosas ou não, o que lhes permite uma circulação internacional. Como sempre, as interpretações culturalistas se mostram, assim, equivocadas.

\section{O Discurso sobre a Democracia Sexual}

Essas campanhas relevam, portanto, uma questão: por que essa epidemia acontece em 2010, e não antes? Afinal de contas, a reação católica estava em andamento pelo menos desde a década anterior. Essa não foi, contudo, a única lógica política à qual os estudos de gênero foram confrontados: a primeira década do novo milênio foi também o palco dos novos nacionalismos sexuais. Na Europa, particularmente, as ideologias nacionalistas antigas, da primeira metade do século $\mathrm{XX}$, combinavam o racismo e a xenofobia com sexismo e à homofobia. Uma dinâmica exacerbada nos países fascistas: as nações valorizavam então uma masculinidade tradicional cuja virilidade repousava sobre a exclusão simultânea de homossexuais e judeus. Ao contrário, as novas retóricas nacionalistas que emergiram nos anos 2000, particularmente na Europa, invocaram os direitos das mulheres e das minorias sexuais para desenhar fronteiras entre um "nós" - supostamente feminista e gayfriendly - e um "eles" - migrantes e mulçumanos, todos presumidamente sexistas e homofóbicos.

Isso significa que no início do século havia dois discursos conservadores concorrentes, e potencialmente contraditórios, acerca do que eu propus nomear de "democracia sexual" (FASSIN, 2005) - - ou seja, a extensão à ordem sexual de uma lógica democrática que reivindica 
que as sociedades definam as suas próprias normas e leis, em vez de confiar em princípios transcendentais tais como Deus, Natureza, Tradição, ou mesmo, Ciência. Por um lado, para o Vaticano, a imanência da democracia sexual ameaça os fundamentos "naturais" da ordem sexual. Por outro lado, para os novos nacionalismos sexuais, a democracia sexual assume um significado positivo ao definir ostensivamente as "nossas" identidades nacionais em oposição à cultura "deles". Para o primeiro, a preocupação principal é o gênero; para os outros, é a raça. Na França, a tensão era evidente durante a luta contra o casamento civil igualitário (Mariage pour tous): católicas e católicos antigênero deveriam fazer alianças com mulçumanas e mulçumanos conservadores ou, ao contrário, esses e essas deveriam ser excluídos e excluídas em nome de uma identidade nacional?

Essa aparente contradição estava prestes a ser resolvida com a ascensão, em várias partes do mundo, de políticas ditas “populistas”, com uma ênfase especial na Europa e na América Latina (CORREA; KALIL, 2020; KUHAR; PATERNOTTE, 2017). De Donald Trump nos Estados Unidos à Viktor Orbán na Hungria, o racismo e a xenofobia, longe de serem incompatíveis com o sexismo e a homofobia, coexistem e até mesmo se completam. Trata-se de um retorno aos velhos nacionalismos sexuais. Convém, assim, qualificar os populismos de direita de neofascistas. Nesse sentido, o Brasil de Jair Bolsonaro se tornou vanguardista de um movimento internacional. O que explica porque o assassinato, em 2018, de Marielle Franco, militante das classes populares, mulher negra da favela, feminista e lésbica, tornou-se imediatamente um poderoso símbolo dessa perversa interseccionalidade neofascista.

Por que o populismo? A chave é o anti-intelectualismo. Os discursos populistas repousam sobre um antagonismo - ou agonismo, para citar a filósofa Chantal Mouffe (2020) em sua defesa por um "populismo de esquerda" - entre "o povo" e "as elites". Mas as versões populistas de direita investem mais contra as elites culturais do que contra as elites econômicas. Evidentemente, trata-se de uma arma já antiga da retórica conservadora. Desde os anos 2000, porém, elas têm tomado um novo fôlego, utilizando a caricatura dos "bobôs" ("bobos")5. Esses são definidos pelo seu capital cultural, invertendo assim a definição marxista de classe com base no capital econômico. Atacar práticas culturais apresentadas

5 Ntd.: O termo francês bobos (bourgeois-bohême) foi forjado por David Brooks, neoconservador americano, para designar uma elite cultural com gostos refinados, mas com tendências politicas à esquerda. O termo foi apropriado na França e é utilizado de forma pejorativa e irônica para designar esse grupo da elite cultural 
como elitistas (de filmes à queijos estrangeiros, passando pelo café importado) é se apresentar como o defensor da "maioria silenciosa", ou a "maioria moral", contra a arrogância das elites culturais.

É fácil compreender como essa retórica política se encaixa tão bem nas campanhas antigênero: a "ideologia de gênero" é atribuída à uma elite intelectual sob influência estrangeira - nos Estados Unidos, da pósmoderna "French Theory", na França, da política identitária "à americana", para utilizar dois exemplos espelhados. Acadêmicas e acadêmicos são assim acusados de fabricar uma linguagem arrogante e obscura a fim de pôr em xeque a realidade da diferença sexual. É o caso do conceito de gênero - o que fica evidente com a insistência da utilização da palavra "teoria": como o darwinismo para os criacionistas, o gênero não é mais do que uma teoria; que não seria, nesse sentido, científica. Como se a ciência não se apoiasse em teorias. Mas esse anti-intelectualismo se estende a um "léxico" mais vasto de "termos controversos" - para retomar a expressão utilizada pelo próprio Vaticano -, como a interseccionalidade, que articula o gênero à raça e à classe.

O nome de um dos coletivos franceses, que se mobilizou contra o casamento igualitário (Mariage pour tous) e que se apresentou como uma reação "popular", resume bem essa ideia: o "Senso comum" ("Sens commun"). Para conservadoras e conservadores, invocar a natureza parece simplesmente... natural! Essa expressão permite confundir as duas definições da biologia - de um lado, os corpos vivos e, de outro, a ciência que os estuda. É assim que a ciência pode ser representada como a simples confirmação de um saber comum; ela não faria nada além de repetir, de maneira tautológica, o que todo mundo já sabe - os homens são homens e as mulheres, mulheres; é preciso, então, de um homem e de uma mulher para fazer uma criança. Obviamente, há variações nacionais e regionais, bem como políticas, e as retóricas podem variar ou mesmo discordar. O Vaticano entendeu muito bem essas lógicas, a partir do momento em que joga com vocabulários diversos - de "ecologia humana" a "colonização ideológica" -, tornando nebulosas as fronteiras entre discursos conservadores e progressistas - quer sejam ecologistas ou antiimperialistas.

Como devemos interpretar o fato de que as campanhas antigênero se propagam internacionalmente, ao mesmo tempo que os populismos? A hipótese aqui é que este fenômeno está relacionado com o contexto global do neoliberalismo nos anos 2010. Depois de 1989 e da queda do muro de Berlin, na Europa, o triunfo do neoliberalismo econômico vem sendo 
geralmente apresentado como a vitória final do liberalismo político, como se os mercados e a democracia fossem inseparáveis. O que coloca em destaque a questão do apoio à democracia sexual, que passou a ser considerada como um teste para as democracias ocidentais - e mais tarde, nos anos 2000, instrumentalizadas pelas políticas de imigração para preservar a "Europa fortaleza".

\section{A aliança do neoliberalismo e do neoconservadorismo}

Na década que se finda, a resistência às políticas neoliberais, tendo se desenvolvido em inúmeros países, desliza no sentido do iliberalismo. $\mathrm{O}$ que não se limita a dirigentes como V. Orbán, que defende abertamente a "democracia iliberal"; uma virada autoritária se deu igualmente no âmbito dos regimes que pretendem defender a democracia liberal, como a França de Emmanuel Macron. Na América Latina, onde o neoliberalismo foi introduzido à força, pela primeira vez, através do golpe de Estado do General Pinochet em 1973, esse tipo de transição não é uma surpresa: nesse continente, a confusão que acontece comumente na Europa, entre o neoliberalismo e liberalismo político, não foi uma opção.

Tal qual o Chile fora um laboratório neoliberal nos anos 1970, na década de 2010 - após o duplo golpe de Estado, que destituiu Dilma Rousseff da presidência e condenou Luiz Inácio Lula da Silva à prisão - o Brasil se tornou o novo laboratório interseccional do neoliberalismo (FASSIN, 2019b): a retórica antigênero e, de modo mais geral, as ideologias anti-intelectuais, desviam o ódio das elites econômicas para transformá-las em ressentimento contra as elites culturais (FASSIN, 2019a) - como se teóricas e teóricos feministas, queer e antirracistas fossem a fonte real da opressão do "povo". Nesse contexto, não é uma surpresa que a Europa e a América Latina convirjam hoje em uma lógica comum de neoliberalismo iliberal, com ecos de campanhas antigênero em ambos os continentes.

Uma questão permanece: como as lógicas neoliberais e neoconservadoras podem convergir no que é frequentemente percebido como uma aliança profana? Afinal de contas, somos habituadas e habituados a pensar que a moral e os mercados são incompatíveis. Na melhor das hipóteses, vemos neoliberais, conservadoras e conservadores como uma parceria estranha - ignorando o papel do protestantismo segundo Max Werber e, mais precisamente, dos cristãos evangélicos hoje 
na promoção do capitalismo. De maneira mais ampla, tendemos a separar as questões econômicas das questões que qualificamos de "culturais" - ou seja, "identitárias" (em termos de identidade, não em termos de capital cultural). Consequentemente, a distinção entre classe e gênero, ou entre classe e raça, pode conduzir a uma oposição entre "redistribuição" e "reconhecimento". Mas o contexto atual convoca à revisão dessas divisões binárias (BROWN, 2019).

Em primeiro lugar, o neoliberalismo também versa sobre valores familiares. Longe de ser amoral, o programa neoliberal sempre incluiu uma dimensão moral. A razão é simples: se o Estado Providência deve desaparecer, as famílias terão de assumir esse papel. O que é frequentemente descrito como uma lógica individualista deve ser compreendida como uma forma de privatização, ou seja, de transferência da responsabilidade do Estado para a família (COOPER, 2017). É por isso que a moral é importante na lógica econômica do capitalismo: torna as famílias responsáveis pelos fracassos individuais. Evidentemente, isto não significa que a política neoliberal e a política neoconservadora são a mesma coisa; senão, como poderíamos entender o momento neoliberal de democracia sexual que precedeu o momento antigênero? Contudo, essa convergência é uma possibilidade que não deveria ser percebida como uma contradição.

Em segundo lugar, essa evolução traz consequências às políticas de resistência às mobilizações antigênero. Há mais de vinte anos, uma controvérsia intelectual importante opôs Judith Butler e Nancy Fraser: se essa insistia na distinção - e na complementariedade - entre redistribuição e reconhecimento, aquela temia que isso conduzisse à priorização da política de classe sobre a política de minorias. J. Butler insistiu no fato de que a política queer não é "meramente cultural", que nunca é puramente simbólica (BUTLER, 1997; FASSIN; FASSIN, 2019c; FRASER, 2013). De fato, o "casamento homossexual" também inclui aspectos materiais. No momento neoliberal atual, vale à pena salientar que a recíproca é igualmente verdadeira: as lutas de classe nunca são "apenas econômicas". Na França, os "coletes amarelos" ("gilets jaunes") 6 tem se mobilizado tanto pela redistribuição como pelo reconhecimento: como mostra simbolicamente sua indumentária fluorescente, visibilidade também faz parte de suas demandas por melhores condições de vida.

\footnotetext{
${ }^{6}$ Ntd.: Éric Fassin trata com um pouco mais de detalhes do movimento dos "coletes amarelos" ("gilets jaunes") na França, na entrevista realizada com Larissa Pelúcio e Diego Paz, publicada em formato de artigo (PELÚCIO; PAZ, 2019).
} 
Isso significa que, nesse momento de iliberalismo neoliberal que nos encontramos, não podemos mais pensar a política nos termos de ontem. Mesmo que nos pareça contraintuitivo, as mobilizações antigênero podem ser entendidas como uma oportunidade intelectual, e, portanto, política. Por um lado, as similaridades entre as situações europeias e latinoamericanas poderiam contribuir a desprovincializar a Europa: nós, europeias e europeus, devemos prestar mais atenção ao que se passa na América Latina. Mas, é claro, o paralelo se revelará elucidativo para ambos os lados. Por outro lado, devemos ultrapassar as antigas alternativas: E por outro lado, precisamos ir além das antigas alternativas: a oposição, mesmo a distinção entre "econômico" e "cultural" pode ter se tornado irrelevante nesse momento neoliberal do capitalismo onde o capital humano é objeto de investimento e de especulação. Essa é a lição final a ser aprendida com a cooptação de ataques religiosos contra "a ideologia de gênero" pelo populismo político anti-intelectualista em um contexto de neoliberalismo iliberal interseccional.

\section{Referências}

BROWN, Wendy. In the ruins of neoliberalism: the rise of antidemocratic politics in the West. New York: Columbia University Press, 2019.

BUTLER, Judith. Merely Cultural. Social Text, n. 52/53, p. 265-277, 1997.

COOPER, Melinda. Family values: between neoliberalism and the new social conservatism. New York: Zone Books, 2017.

CORRÊA, Sonia; KALIL, Isabela. Políticas antigenéro en América Latina: Brasil - ¿La catástrofe perfecta? Rio de Janeiro: ABIA - Asociación Brasileña Interdisciplinar de SIDA, 2020.

FASSIN, Éric. Démocratie sexuelle. Comprendre, revue de philosophie et de sciences sociales, n. 6, p. 263-276, 2005.

FASSIN, Éric. Populismo e ressentimento em tempos neoliberais. Tradução: Heloisa Martins Costa. Rio de Janeiro: Eduerj, 2019a.

FASSIN, Éric. Brasil: o laboratório interseccional do neoliberalismo. Cult, 22 out. 2019b. Vol XX, N. XX - Mês. - Mês., Ano https://portalseer.ufba.br/index.php/cadgendiv 
FASSIN, Éric. Merely economic? Rassegna Italiana di Sociologia, $\mathrm{n}$. 4/2019, 2019c.

FRASER, Nancy. Fortunes of feminism: from state-managed capitalismo to neoliberal crisis. London: 2013.

GARBAGNOLI, Sara; PREARO, Massimo. La croisade "anti-genre": du Vatican aux manifs pour tous. Paris, France: Éditions Textuel, 2017.

KUHAR, Roman; PATERNOTTE, David. (EDS.). Anti-gender campaigns in Europe: mobilizing against equality. London; New York: Rowman \& Littlefield International, Ltd, 2017.

MOUFFE, Chantal. Por um Populismo de Esquerda. 1ed. São Paulo, SP: Autonomia Literária, 2020.

PELÚCIO, Larissa; PAZ, Diego. "A democracia sexual no coração da democracia". A centralidade do gênero para a leitura do presente entrevista com Éric Fassin. Revista Interface - Comunicação, Saúde, Educação. Botucatu, v. 23, n. e190258, p. 1-12, 2019 


\section{Campagnes anti-genre, populisme et néolibéralisme en Europe et en Amérique latine}

RESUMEN/ABSTRACT: Cet article a été d'abord publié sous le titre Anti-gender Campaigns, Populism, and Neoliberalism in Europe and Latin America dans la revue Lasa Forum dans le dossier Las ofensivas antigénero em América Latina $(51,2,67-71)$, puis en francais sous le titre Campagnes anti-genre, populisme et néolibéralisme en Europe et en Amérique latine, dans La Revue Internationale et Stratégique (RIS), au sein du dossier thematique La géopolitique par le genre: des réflexions aux nouveaux répertoires d'action (119, 3, 79-87).

Palabras Clave/Keywords: Anti-genre. Populisme. Neoliberalisme. France. Brésil.

\section{Éric FASSIN (Autor)}

Professor de sociologia na Universidade de Paris 8 (Departamento de Estudos de Gênero e no Departamento de Ciências Políticas) e pesquisador no Laboratório de estudos de gênero e de sexualidade (Laboratoire d'études de genre et de sexualité, LEGS).

Marina Duarte (Tradutora)

Pós-doutoranda na Universidade Paris 8 no Laboratório de estudos de gênero e de sexualidade (Laboratoire d'études de genre et de sexualité, LEGS); doutora em História pela Universidade Paris Diderot - Paris 7 e doutora em Ciências Sociais em cotutela pela Universidade estadual de São Paulo.

\section{Diego Paz (Tradutor)}

Doutorando em psicologia, na Universidade católica de Pernambuco (Recife, PE, Brazil), e em ciências políticas - especialidade estudos de gênero, na Universidade Paris 8 (Paris, França); membro do Laboratório de estudos de gênero e de sexualidade (Laboratoire d'études de genre et de sexualité, LEGS).

Recebido em: 30/12/202O

Aprovado em: 22/o1/2021 